\title{
Supporting a transition towards sustainable circular economy: sensitivity analysis for the interpretation of LCA for the recovery of electric and electronic waste
}

\author{
Lucia Rigamonti ${ }^{1} \cdot$ Alida Falbo $^{1} \cdot$ Luca Zampori $^{2} \cdot$ Serenella Sala $^{2}$ (i)
}

Received: 26 November 2015 / Accepted: 14 November 2016/Published online: 7 December 2016

(C) The Author(s) 2016. This article is published with open access at Springerlink.com

\begin{abstract}
Purpose The interpretation is a fundamental phase of life cycle assessment (LCA). It ensures the robustness and the reliability of the overall study. Moving towards more circular economy requires that different waste management options are systematically scrutinized to assess the environmental impacts and benefits associated to them. The present work aims at illustrating how a sensitivity analysis could be applied to the impact assessment step supporting the interpretation of a LCA study applied to a waste management system that includes material recovering. The focus is on toxicity-related and resource-related potential impacts as they are considered among the most critical ones, which may affect the way the final benefit from material recovery is evaluated.

Methods Possible alternatives in terms of impact assessment assumptions and modelling are tested by performing a sensitivity analysis on a case study on electric and electronic waste. For the toxicity-related impact categories, first, a sensitivity analysis is performed using different sets of characterization factors for metals aiming at identifying how they are affecting the final results. Then, an analysis of the relative contribution of long-term emissions in upstream processes is carried out
\end{abstract}

Responsible editor: Zbigniew Stanislaw Klos

Electronic supplementary material The online version of this article (doi:10.1007/s11367-016-1231-5) contains supplementary material, which is available to authorized users.

Serenella Sala

serenella.sala@jrc.ec.europa.eu

1 Department of Civil and Environmental Engineering, Politecnico di Milano, P. L. da Vinci 32, 20133 Milan, Italy

2 European Commission, Joint Research Centre, Directorate D: Sustainable Resources, Bioeconomy Unit, via Enrico Fermi 2749, 21027 Ispra, VA, Italy aiming at unveiling critical issues associated to their inclusion or exclusion. For the resource depletion impact category, a sensitivity analysis has been performed, adopting different sets of characterization factors based on existing models for minerals and metals as well as recently proposed sets accounting for critical raw materials.

Results and discussion The indicator of the ecotoxicity impact category obtained by applying the updated characterization factors is about three times higher than the corresponding obtained by the USEtox model. The long-term emission result is responsible for the major part of all the toxicity impact indicators. Moreover, for the ecotoxicity indicator, excluding the long-term emissions changes the total results from being negative into positive. The sensitivity analysis for the resource depletion impact category shows that all the models applied result in a total avoided impact. A quantitative comparison among all the results is not possible as the different models use different units of measure.

Conclusions The application of LCA is crucial for assessing avoided impacts and uncovers potential impacts due to recycling. However, contrasting results may stem from the application of different assumptions and models for characterization. A robust interpretation of the results should be based on systematic assessment of the differences highlighted by the sensitivity, as guidance for delving into further analysis of the drivers of impacts and/or to steer ecoinnovation to reduce those impacts.

Keywords Circular economy · Electronic waste · Interpretation $\cdot$ LCA $\cdot$ Resource recovery $\cdot$ Toxicity

\section{Introduction}

Circular economy (CE) is a central concept in the current debate on sustainable production and consumption. CE could 
be defined as an economic model based on resource optimization while promoting the use of waste as resource. Within more circular economies, the resources are used efficiently within the life cycle of a product and the wastes generated along the supply chains are minimized and used as much as possible, directly or after transformation, as input to other products and systems. Supporting a transition towards circular economy means improving the analysis of resource flows within sectors and products, defining and implementing new ecodesign strategies, ensuring low toxicity in products and waste as well as fostering waste prevention and recovery.

Life cycle assessment (LCA) methodology may support the analysis of the impacts and benefits associated to recycling, and in the literature, there are several examples of application (among others, Brogaard et al. 2014 and Rigamonti et al. 2010). The basic idea is to ensure that the recovery of material is not posing additional burdens on the environment to an extent to which benefits are offset. The analysis should be conducted in a multi-indicator setting, beyond a mere energy-related perspective, including impacts in different impact categories.

Indeed, to ensure consistency and robustness of the results, LCA should be critically applied, especially focusing on the interpretation of the results. The importance of a proper interpretation of the results of an LCA study is recognized by relevant standards, guides and research articles.

Interpretation is one of the four phases identified in the ISO 140402006 standard and the ISO 140442006 standard, which require interpretation of life cycle inventory (LCI) and life cycle impact assessment (LCIA) phases according to the goal and scope of the study. Furthermore, a sensitivity check of significant inputs, outputs and methodological choices shall be performed.

The Product Environmental Footprint (PEF) guideline (EC 2013) explains that the interpretation of the results of a PEF study serves two purposes: (1) to ensure that the performance of the PEF model corresponds to the goals and quality requirements of the study, in this sense, PEF interpretation may inform iterative improvements of the PEF model until all goals and requirements are met; and (2) to derive robust conclusions and recommendations from the analysis, for example, in support of environmental improvements.

Several authors have provided evidence that interpretation is one of the key steps of an LCA study and provides guidance and/or recommendations depending on the purpose of the study. Initially, it was recognized that interpretation was not one of the hot topics in literature studies (Heijungs and Kleijn 2001), and authors provided numerical techniques for interpretation. More recently, other authors, such as Gaudreault et al. (2009), while recognizing that LCA has become an important methodology for more sustainable process design, observed that its application in a decision-making context has been limited by a poor understanding of methodological choices and assumptions; therefore, they recommend careful interpretation of the results to improve the quality of the outcome (i.e. improve the decision-making process). This view is shared by authors such as Prado-Lopez et al. (2014), who have identified the lack of robust methods of interpretation to support decision makers; hence, they provide a novel approach based on a multi-criteria decision analytic method (stochastic multi-attribute analysis for life cycle impact assessment (SMAA-LCIA)) which in their view should support both interpretation of the results and the decision-making process. Van Hoof et al. (2013) explained how normalization helps maintain a multi-indicator approach while keeping the most relevant indicators, allowing effective decision-making. Finally, other authors, such as Cellura et al. (2011) and Huang et al. (2013), performed LCA of specific products (tiles and road pavements) and they pointed out the relevance of sensitivity analysis to strengthen the reliability of the results obtained and draw conclusions to support sector-specific guidelines.

Given the risks associated with the interpretation of the results, when adopting a single model in the evaluation of burdens and benefits, there is the need of specific guidelines on what should be taken into account when running an LCA case study. This is particularly relevant when there are expected benefits associated to certain interventions (e.g. recycling), whereas also burdens may arise from the system under consideration, potentially offsetting the benefits. The present work aims at illustrating how a sensitivity analysis using different impact assessment models and characterization factors (CFs) in the impact assessment phase may help the interpretation of an LCA study applied to a waste management system that includes recycling, unveiling possible critical elements and challenges. The study is based on a previous paper (Biganzoli et al. 2015), where a more in-depth analysis related to human toxicity-cancer effects and freshwater ecotoxicity category indicators was identified as a priority area. Therefore, we tested possible alternatives in terms of impact assessment assumptions and modelling, performing a sensitivity analysis on a case study on electric and electronic waste. The focus was on toxicity-related and resource-related potential impacts as they are considered among the most controversial ones, which may affect the way the final benefit from material and energy recovery is evaluated.

The paper is organized as follows: in Sect. 2, the methodology for the sensitivity analysis is illustrated along with the description of the specific case study selected for the testing. In Sect. 3, the results of the testing are reported and discussed, highlighting the major challenges for the result interpretation.

\section{Methodology}

The methodology for supporting the interpretation of the results has been focused on resource-related and toxicity-related 
impact categories. A testing phase has been performed through sensitivity analyses in order to highlight where there are critical aspects which may undermine results and interpretation thereof.

We selected a case study in which LCA has been applied to assess a waste electrical and electronic equipment (WEEE) management system (Biganzoli et al. 2015). The case study has been run using International Reference Life Cycle Data System (ILCD) methodology (EC-JRC 2010), currently recommended for the EU context and for the PEF (EC 2013) as life cycle impact assessment method. Currently, the models used in several impact categories are subject to a process of revision based on testing the strengths and weaknesses of available models. Therefore, we tested several options of interest for the evaluation of benefits associated to recycling, selected based on the extent they are debated within circular economy context (e.g. resource recovery and toxicity-related impacts).

The methodological steps are detailed in Sect 2.1, whereas the case study is described in Sect. 2.2.

\subsection{Rationale for defining the sensitivity analysis for the impact assessment phase}

Firstly, we tested impact characterization models and characterization factors $(\mathrm{CFs})$ for toxicity-related impact categories: human toxicity (cancer and non-cancer) and ecotoxicity. Toxicity-related impact categories are already considered relevant for the recycling processes (Lim and Schoenung 2010). However, there is an evolving debate on the robustness of these impact categories and specifically for what concern impacts due to metals (see e.g. Pizzol et al. 2011). In fact, some specific features of the metals (e.g. metal essentiality), as well as elements affecting their fate modelling (e.g. different conditions affecting their bioavailability), are not fully captured by currently available models applied in LCA. Those aspects are also affecting the USEtox model (Rosenbaum et al. 2008) currently recommended within the ILCD methodology. Different sets of CFs have been proposed for metals (such as Gandhi et al. 2011 and Dong et al. 2014) to improve the way in which metals are characterized and are now included in USEtox version 2. Additionally, long-term emissions are already identified as a relevant aspect to be taken into account in life cycle inventories and impact assessment, especially concerning emission of metals in specific contexts (e.g. mining and landfilling) (Bakas et al. 2015). The results of toxicity impact categories may vary for several orders of magnitude (e.g. the case study presented by Huijbregts et al. 2003 in which the toxic impact of metals is reported to differ more than six orders of magnitude depending on the time horizon chosen). A guideline for their treatment in the context of EU recommendation is needed based on the recent literature (e.g. Pettersen and Hertwich 2008; Hauschild et al. 2008; Clavreul et al. 2012), given the prominence of these emissions in the characterized results. Hence, we performed:

- a sensitivity analysis, where updated CFs for metals were tested, along the lines of the recent literature (Dong et al. 2014), aiming at identifying the differences in the results of ecotoxicity associated to metals.

- an analysis of the relative contribution of long-term emissions in upstream processes aiming at identifying effects in the assessment due to presence of long-term emissions of metals.

Secondly, we tested impact assessment models for the resource depletion impact category. Models currently available differ both in the modelling approach, in the perspective adopted for assessing the resources (Dewulf et al. 2015) and, as consequence, in the metric and factors adopted for the characterization (Mancini et al. 2015a). Beyond the potential benefit associated to a mass-based approach to recycling (e.g. kilogramme of material recycled), there is indeed the need of understanding to which extent the recycled materials are contributing to the resource depletion impact category.

Traditionally, LCIA models focusing on resource depletion have been based on different assumptions (Steen 2006), namely: (1) assuming mining cost being a limiting factor, (2) assuming increasing demand of energy due to extraction from low-grade sources, (3) assuming that scarcity is a major threat and (4) assuming that environmental impacts from mining and processing of mineral resources are the main problem. The characterization models express the available amount of a resource at a given point in time (e.g. ore deposits or fossil fuel reserves) or the future consequences (e.g. higher economic and/or energetic costs) of the extraction of a certain amount of a resource in the present. Furthermore, in business and policy context, there is an increasing need of assessing the so-called critical raw materials (CRMs), having a strategic economic role for certain sectors (Mancini et al. 2015b) and for which a set of $\mathrm{CFs}$ has been recently proposed (Mancini et al. 2016).

Therefore, we performed the sensitivity analysis on the resource-related impacts adopting different sets of CFs based on existing models, including a model for CRM's.

The different sets of CFs based on existing models that we tested are mainly based on the review of Klinglmair et al. (2014). We tested abiotic depletion potential (ADP) (CML 2012), which is focusing on potential resource depletion based on the ratio between resource consumption and availability (either considering ultimate reserves in the earth crust, known base reserves or economically viable reserves); ILCD model (EC-JRC 2010), which is an extended version of CML 2012 reserve based (based on CML algorithm, few other resources have been added by (Sala et al. 2012)); EDIP97 (Hauschild and Wenzel 1998), which is comparing the resource with the 
deposits economically exploitable, without accounting for current level of consumption; EPS2000 (Steen 1999), which is assessing the cost (as the society's willingness to pay) of substituting a resource by an alternative for future generations affected by the current level of depletion; ReCiPe 2008 (Goedkoop et al. 2009), which is assessing the marginal increase of extraction cost per kilogramme of extracted resource, differentiating it by deposit and assuming a discount rate over an indefinite time span; the anthropogenic stock extended abiotic depletion potential (AADP, Schneider et al. 2011), which is accounting for the potential of resource recycling, assuming urban mining as an additional source of resources. The recent update of the AADP (2015) (Schneider et al. 2015) was also considered. It introduces the concepts of "ultimately extractable reserves" represented by the amount available in the upper earth's crust that is ultimately recoverable.

Regarding CRMs, the sets of CFs recently developed by Mancini et al. (2016) have been tested. This is of particular relevance for a case study related to WEEE giving the number of CRMs, both metals and materials, which currently lacks CFs in LCIA and which may represent a further benefit of recycling to be accounted for. The new CFs benefitted from the results of a workshop exploring the role of LCA for the accounting and the assessment of CRMs (Mancini et al. 2013). The characterization model is based on the use and adaptation to LCA of the supply risk indicators developed by the European Commission (EC 2014). Among those proposed by Mancini et al. (2016), three sets of CFs are tested, based on different assumptions: (1) a baseline option, the supply risk factors as such-(SR); (2) an exponential function which magnifies the differences between the CRMs$(\mathrm{SR})^{\wedge} 6$ and (3) the ratio between supply risk and production data (SR/world mine production in 2011), which reflects the size of the market, giving more importance to the materials used in small amounts in products and applications, like, e.g. specialty metals that are often perceived as critical.

\subsection{Case study on WEEE}

The LCA of the WEEE management system implemented in the Lombardy region (Italy) and described by Biganzoli et al. (2015) was taken as a case study. In that study, the assessment was carried out to quantify the mass balance of the WEEE management system in the Lombardy region in the year 2011 and to calculate its environmental benefits and burdens. All the five categories of WEEE (i.e. according to the Italian legislation, heaters and refrigerators - R1, large household appliances_-R2, TV and monitors_-R3, small household appliances - R4 and lighting equipment - R5) were included in the analysis. The main goal was the assessment of the environmental performance of the treatment of each WEEE category, with the aim to understand if the benefits arising from the material and energy recovery were offsetting the burdens due to the processing of the waste itself.

The present study focuses on the management of the small household appliances (R4). This WEEE category was specifically selected as it is the most heterogeneous one and includes various components (e.g. printed wiring boards, base metals, different types of plastics, etc.), none of which is predominant.

The functional unit (FU) was defined as the treatment of $1 \mathrm{t}$ of R4. The system boundaries included all the treatment processes, from the moment the waste enters the first treatment plant to when it leaves the system as an emission (solid, liquid or gaseous) or as secondary raw material, following the "zero burden assumption" (Ekvall et al. 2007). They thus included the preprocessing at the first treatment plant and the subsequent treatment of the separated components in recycling/ disposal of final plants. The collection and the transport to the first treatment plant were excluded from the system boundaries, as their impacts resulted negligible in the previous study (Biganzoli et al. 2015).

Due to the complexity of the treated waste, it was not possible to quantify the kind of materials entering the system based on their composition; consequently, it was not possible to quantify how much of a specific element (e.g. gold, silver, etc.) was lost during the recycling processes. Literature studies, such as the UNEP reports (UNEP 2011 and 2013), can complement the missing information, by providing typical compositions and recovery rates, but they were not applied in the specific case analysed, which focused only on the amount of materials recovered. The available information to date are mainly related to the typologies of materials which are recycled. For the specific case study, Table A1 of the Electronic supplementary material shows the amount of each component separated in the first treatment plant, together with its destination.

Cases of multi-functionality were resolved by expanding the system boundaries to include avoided productions due to material and energy recovery from waste (EC-JRC 2010; Finnveden et al. 2009). Avoided primary material and energy productions were based on average technologies. Table A2 of the Electronic supplementary material shows the amount of avoided primary materials and energy associated with the treatment of $1 \mathrm{t}$ of R4.

For each process, a new module was designed in the SimaPro software, including the energy and material consumption, the direct emissions as well as the substituted materials and energy, with the same approach adopted in previous studies (Rigamonti et al. 2010; Rigamonti et al. 2013a, b). Primary data were used in the modelling of the foreground system, in particular, for the mass and energy balances of the first treatment plant and of the treatment of some of the separated components. These data derived from the Italian regional database O.R.So. (Osservatorio Rifiuti Sovraregionale) and from field visits to the main treatment plants located in the 
Lombardy region. For some components, primary data were not available and so data from the literature and from the ecoinvent database version 2.2 (Swiss Centre for Life Cycle Inventories 2010) were used.

The life cycle impact assessment step was performed as explained in Sect. 2.1.

\section{Results and discussion}

\subsection{Testing impact assessment models and characterization factors of toxicity-related impact categories}

\subsubsection{Dong et al. 2014 vs USEtox}

The indicator of the impact category ecotoxicity, expressed per $1 \mathrm{t}$ of $\mathrm{R} 4$, results $-1.04 \mathrm{E}-4$ PAF day $\mathrm{m}^{3}$ if applying the CFs of Dong and $-1.24 \mathrm{E}-5$ PAF day $\mathrm{m}^{3}$ when applying the USEtox model as implemented in the ILCD method v.1.05. We underline that Dong et al. (2014) report CFs only for freshwater compartment and have only CFs for 15 metals.

The comparison of the results is reported in Fig. 1, focusing on metals considered in both models (i.e. zinc, lead, copper, chromium, cadmium, beryllium and barium). The total impact obtained by applying Dong et al.'s (2014) CFs results about three times higher than the corresponding impact obtained by the USEtox model. This is mainly due to the Dong et al.
(2014) CFs of copper $(\mathrm{Cu})$ and zinc $(\mathrm{Zn})$ which are higher than those adopted in the USEtox model when considering the freshwater archetype proposed in the paper of Dong et al. as default when the location of the emission is not known.

\subsubsection{Long-term vs short-term emissions}

Figures 2 and 3 show the human toxicity (cancer and noncancer effects) impact indicators and the freshwater ecotoxicity impact indicator relative to the treatment of $1 \mathrm{t}$ of R4. The total values are divided into the two contributions: long-term emissions and short-term emissions.

The long-term emissions are responsible for the major part of the impact. Excluding these emissions, the total values of the indicators change but the qualitative results in terms of benefit or burden for the environment do not change for the human toxicity indicator. The situation is different for the ecotoxicity indicator: in this case, by excluding the longterm emissions, the total value changes from being negative (i.e. a benefit for the environment) into positive (i.e. a burden for the environment). This is because most of the long-term emissions are avoided emissions, associated with the material and energy recovery.

A detailed contribution analysis was carried out to understand better the results associated with the long-term emissions (Figs. B1-B3 and Tables B1-B10 of the Electronic supplementary material).

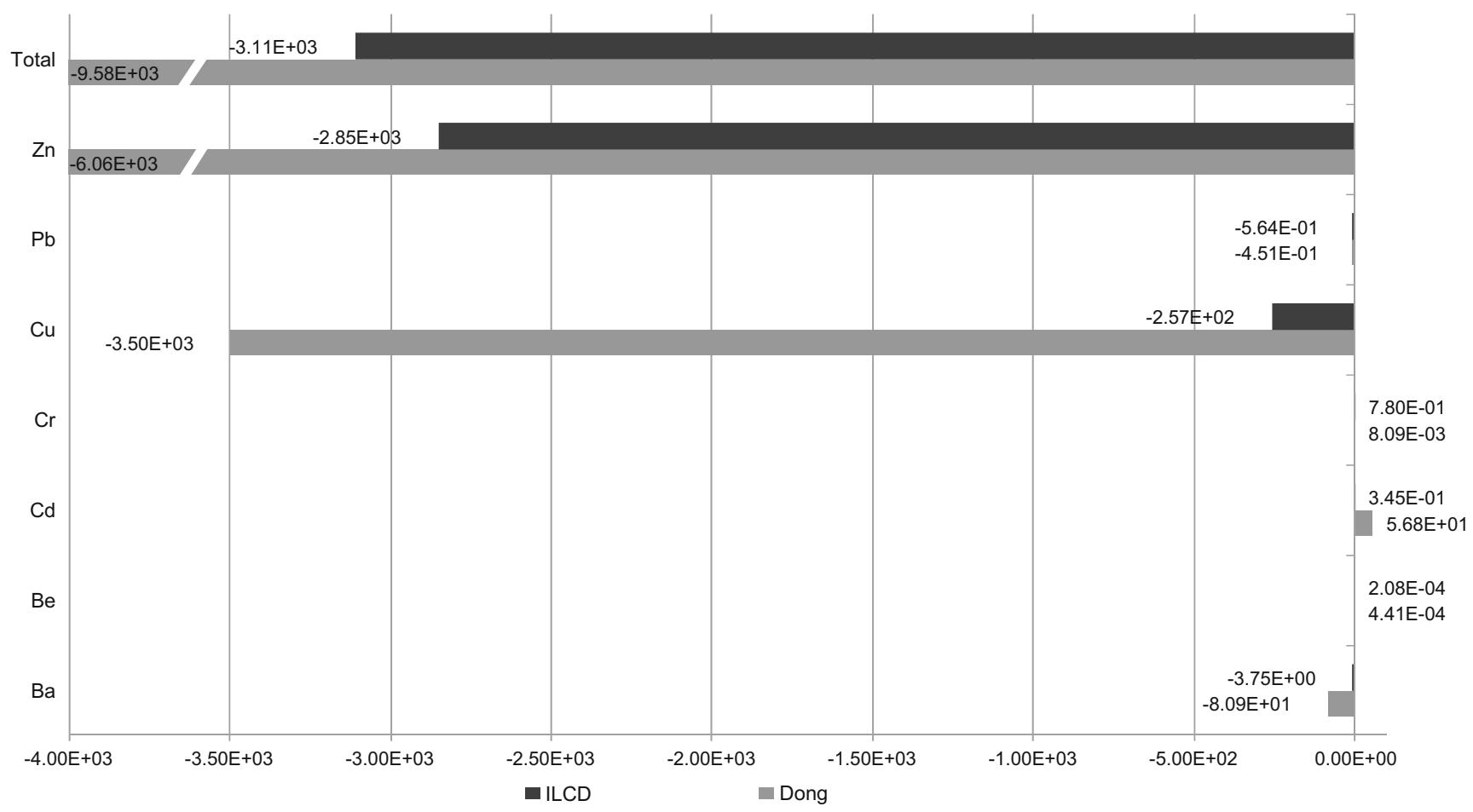

Fig. 1 Freshwater ecotoxicity impact indicator, expressed in PAF day $\mathrm{m}^{3}$, due to the treatment of $1 \mathrm{t}$ of R4 calculated by applying the USEtox characterization factors (as in ILCD) and Dong et al.'s (2014) characterization factors (considering only the metals in common) 


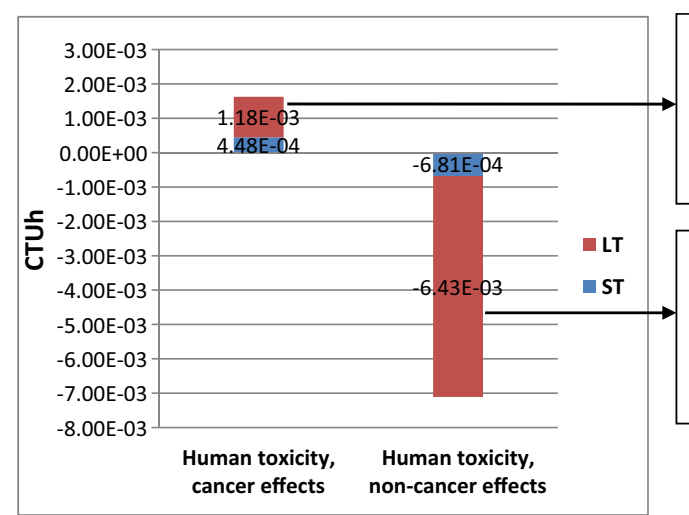

Fig. 2 Human toxicity (cancer effects and non-cancer effects) impact indicators associated with the treatment of $1 \mathrm{t}$ of R4. Total values are divided into short-term emission $(S T)$ and long-term emission (LT)

The recovery of steel and ferrous metals is the main process that contributes to the human toxicity cancer effect impact indicator: most of the long-term emissions derive from the sub-process of disposal of the furnace slag are produced by the ferrous scrap recycling process. The metal causing this result is chromium (VI).

Considering the human toxicity non-cancer effect impact indicator, the main contribution is the recovery of the printed wiring boards. Its sub-process of disposal of sulfidic tailings produced by non-iron metal mining is the main process responsible for the longterm avoided emissions, represented mainly by zinc and arsenic.

The same process, i.e. the recovery of the printed wiring boards, with the same sub-process, is responsible for most of the long-term avoided emissions in the freshwater ecotoxicity impact indicator. Zinc is, in this case, the most important avoided long-term emission.

\subsection{Testing impact assessment models and characterization factors of resource depletion impact category}

The comparison among the different models was, first of all, made considering the mineral resources present in the inventory of the case study covered by each of them. Table 1 contributions. The boxes explain the main processes and the main substances associated with long-term emissions

shows that the ILCD method is the most comprehensive one with 31 mineral resources included in its model for the resource depletion category. On the contrary, the supply risk (3) is the one that covers the minor number of substances (i.e. 7).

A second step of the analysis was the comparison of the sign and the value of the impact indicator. First of all, all the models result in avoided impacts (Table 1). Then, the models that express the indicator with the same unit of measure were compared, i.e. AADP, ILCD and CML 2012. Results are shown in Fig. 4. The biggest avoided impact is associated with the model applied in the CML 2012 (c). This is not so different from the total value obtained by applying the models considered in CML 2012 (b) and ILCD methods. The results of the AADP models are one order of magnitude less. AADP (2011) (Schneider et al. 2011) considers, in fact, a limited number of mineral resources (e.g. it does not include silver that, where considered, gives an important contribution to the avoided impacts, see Fig. 5). AADP (2015) (Schneider et al. 2015) considers more substances than AADP (2011) (Schneider et al. 2011), in a number similar to that of the CML 2012 (c).

Finally, a contribution analysis was performed (Fig. 5 and Table $\mathrm{C} 2$ of the Electronic supplementary material).

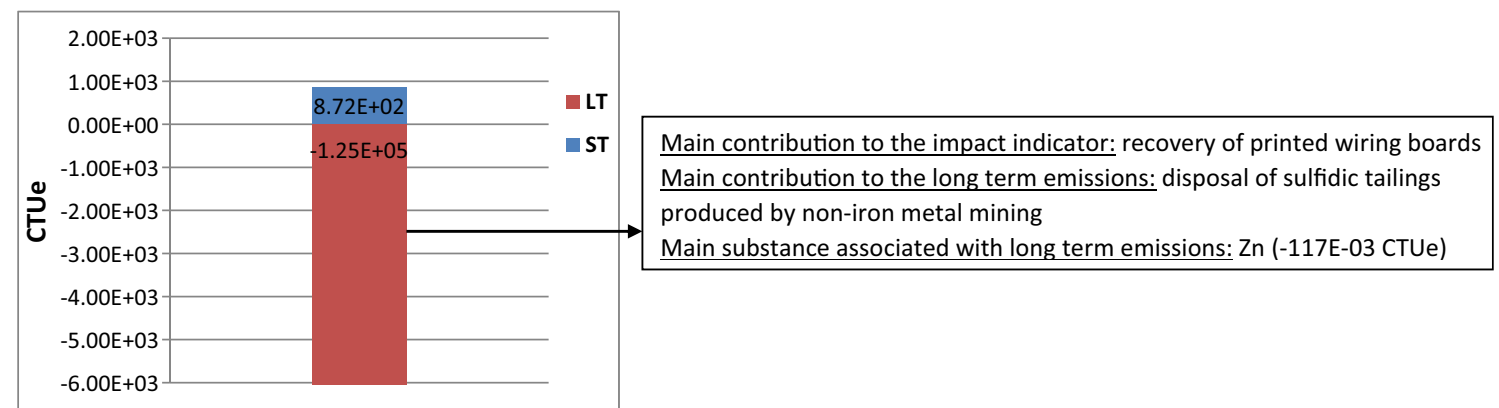

Fig. 3 Freshwater ecotoxicity impact indicator associated with the treatment of $1 \mathrm{t}$ of R4: the total value is divided into short-term emission (ST) and long-term emission (LT) contributions. The boxes explain the main processes and the main substances associated with long-term emissions 
Table 1 Coverage of the selected mineral resources in the selected models and corresponding mineral resource depletion indicator

\begin{tabular}{|c|c|c|c|}
\hline \multirow[t]{2}{*}{ Model } & \multirow{2}{*}{$\begin{array}{l}\text { Total selected mineral } \\
\text { resources (of which } \\
\text { critical raw materials) }\end{array}$} & \multicolumn{2}{|l|}{ Total impact } \\
\hline & & Value & $\begin{array}{l}\text { Unit of } \\
\text { measure }\end{array}$ \\
\hline AADP (2011) & $8(1)$ & $-7.45 \mathrm{E}-01$ & $\mathrm{~kg} \mathrm{Sb-eq.}$ \\
\hline AADP (2015) & $23(7)$ & $-1.53 \mathrm{E}-01$ & kg Sb-eq. \\
\hline ILCD & $31(9)$ & $-2.25 \mathrm{E}+00$ & kg Sb-eq. \\
\hline CML 2012 & $28(8)$ & $-1.01 \mathrm{E}+00$ & kg Sb-eq. \\
\hline CML 2012 & $25(6)$ & $-2.25 \mathrm{E}+00$ & kg Sb-eq. \\
\hline CML $2012^{c}$ & $25(6)$ & $-2.53 \mathrm{E}+00$ & kg Sb-eq. \\
\hline EDIP 97 & $19(4)$ & $-1.38 \mathrm{E}+01$ & PR \\
\hline EPS 2000 & $25(8)$ & $-1.17 \mathrm{E}+05$ & ELU \\
\hline ReCiPe 2008 & $15(3)$ & $-6.85 E+03$ & $\$$ \\
\hline Supply risk (1) ${ }^{\mathrm{d}}$ & $21(8)$ & $-1.97 \mathrm{E}+01$ & SR \\
\hline Supply risk (2) ${ }^{\mathrm{e}}$ & $21(8)$ & $-2.96 \mathrm{E}+00$ & SR \\
\hline Supply risk (3) ${ }^{\mathrm{f}}$ & $7(2)$ & $-1.72 \mathrm{E}+00$ & SR \\
\hline
\end{tabular}

$P R$ person reserves, $E L U$ environmental load units, $S R$ supply risk

${ }^{\mathrm{a}}$ Ultimate reserves

${ }^{\mathrm{b}}$ Base reserves

${ }^{\mathrm{c}}$ Economic reserves

${ }^{\mathrm{d}}$ Baseline option

e $(\mathrm{SR})^{\wedge} 6$

${ }^{\mathrm{f}} \mathrm{SR} /($ world mine production in 2011)
Silver (Ag) gives the main percentage contribution to the indicator in the five models (i.e. CML 2012 versions $b$ and c, ILCD, supply risk (3) and EDIP97). Cobalt (Co) is the main contributor in the supply risk $(2)$, copper $(\mathrm{Cu})$ in the ReCiPe 2008, palladium (Pd) in the EPS 2000 and AADP (2015) Schneider et al. (2015) and nickel (Ni) in the AADP (2011) Schneider et al. (2011). In the CML 2012, (a) tellurium, gold $(\mathrm{Au})$ and silver $(\mathrm{Ag})$ are the most important substances, whereas aluminium $(\mathrm{Al})$, copper $(\mathrm{Cu})$ and nickel $(\mathrm{Ni})$ are the main contributors in the case of the supply risk (3).

These results reveal that the relative importance of one substance compared to another changes with the model. This is because the models differ in the substances that they include and in the CFs of each substance.

\section{Conclusions}

Moving towards more circular economy requires that different waste management options are more and more systematically scrutinized to assess the environmental impacts and benefits associated to them. To ensure that proper decisions are taken on waste streams, LCA plays a crucial role for assessing avoided impacts and uncovers potential impacts due to recycling. However, given the possible limitations of current life cycle impact assessment models, there is the need of conducting extensive sensitivity analysis of the results. In fact, contrasting results may stem from the application of different assumptions and models for characterization. In the present study, we focused on toxicity- and resource-related aspects, being critical in the current debate on fostering circular
Fig. 4 Comparison among the mineral resource depletion indicators expressed in kilogramme Sbeq per $1 \mathrm{t}$ of R4 calculated by different models

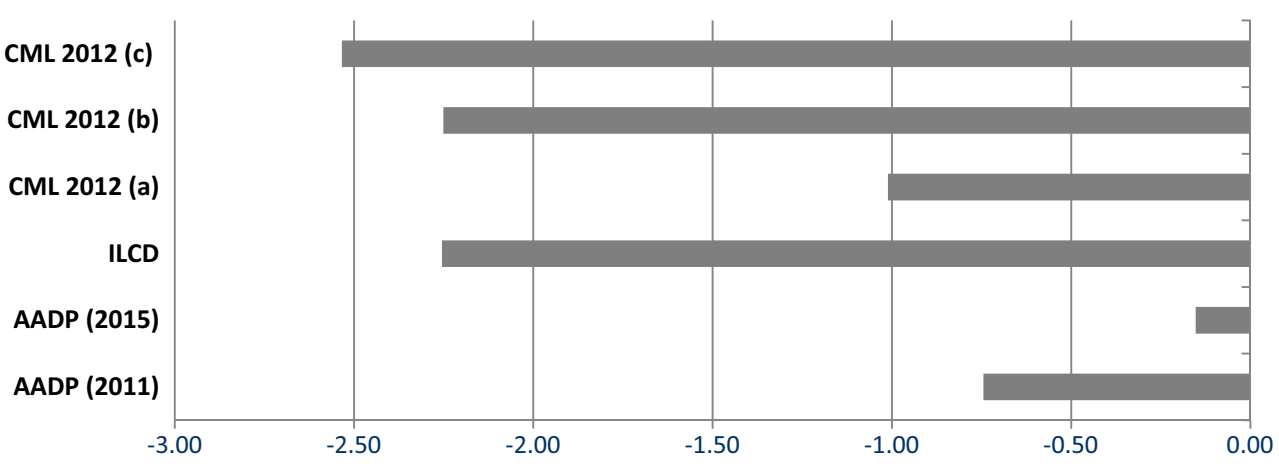




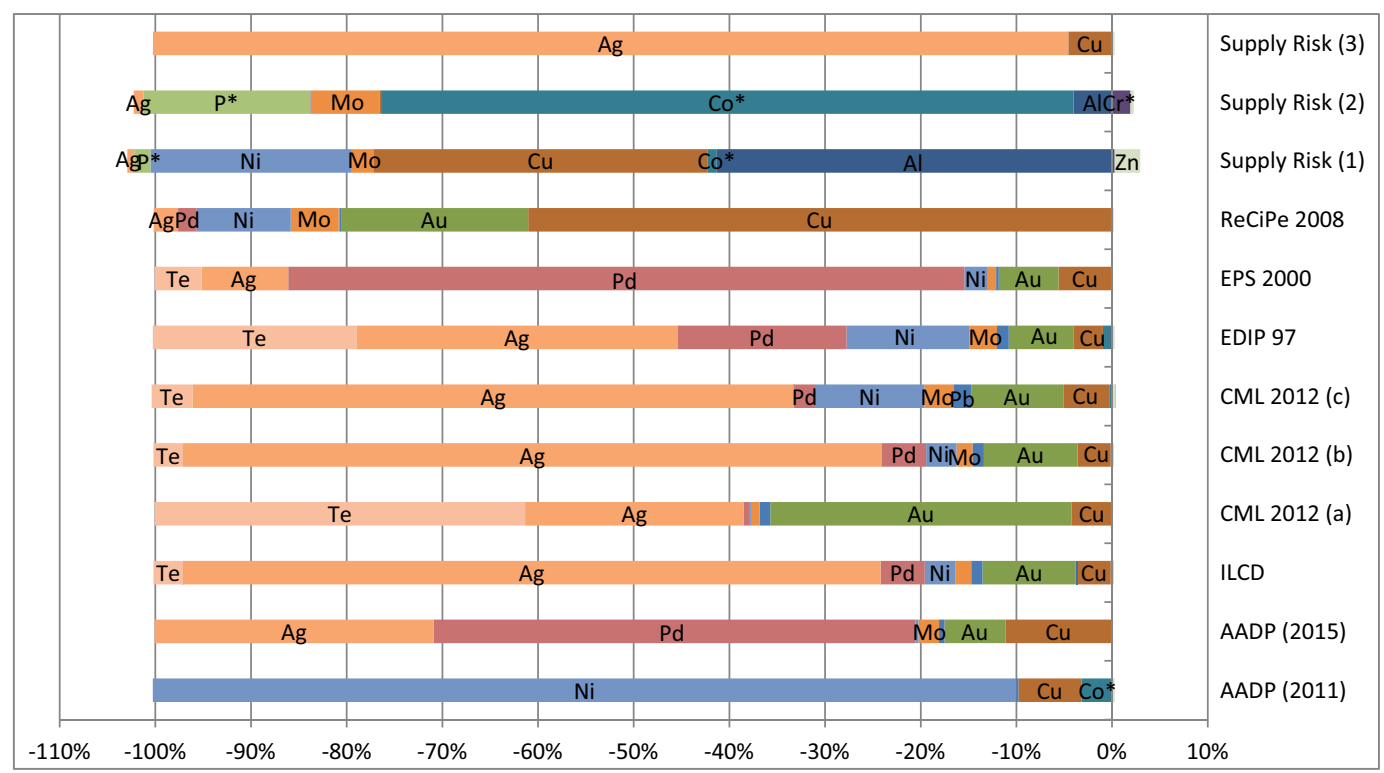

* critical raw materials

Fig. 5 Contribution analysis for the resource-related indicators calculated by different characterization models. The asterisk indicates critical raw materials

economy. A robust interpretation of the results should be based on systematic assessment of the differences highlighted by the sensitivity, as guidance for delving into further analysis of the major drivers of impacts and/or to steer ecoinnovation to reduce the impacts.

The specific results of the current study are related to the R4 waste treatment in the Lombardy region. This means that in other contexts, the recovery of materials and the associated impacts may change. However, some conclusions of general interest and applicability could be drawn.

Regarding the toxicity-related impact categories, the impacts and the avoided impacts for the R4 treatment are focused on metals, a well-known critical issue within LCA. Metal impacts are considered generally overestimated by existing multi-media models adopted in LCA and used for developing the consensus model USEtox. Recent publications, such as of Dong et al. (2014), have improved the theoretical foundation for modelling the impact of metals, discriminating between site-specific conditions which may influence metal fate and bioavailability. However, when the location of the emission is not known and the practitioner is using the proposed default set of characterization factors, the impact of metals is even higher than before for specific substance. This leads again to a dominance of few metals over the overall toxicity-related impacts.

Regarding the long-term emissions, this is again an already known problem in LCA results. A research agenda from the modelling point of view has been already defined including the introduction of time-dependent $\mathrm{CFs}$, explicitly addressing uncertainties and accounting for background concentrations (Bakas et al. 2015). Considering current available models and information, the decision to include or not those emissions should be based on some evidences, such as (i) in comparing short-term and long-term emissions, the latest have very high uncertainties in inventories, and (ii) current characterization models are not able to account for the intensity of the emissions over time. Assessing the results with and without longterm emissions is fundamental for interpreting the results of the contribution analysis.

Regarding the resource impact assessment, it is clear how this assessment is of paramount importance when considering recycling and in general on the possible avoided impacts due to applying circular economy strategies. Beyond the mass accounting (e.g. kilogramme of material recovered for any tonne of waste treated), there is an increasing interest in understanding the relative importance of the materials recovered. Applying more traditionally, depletion-oriented models, some materials are popping up as major contributors. However, the practitioner should be aware that those models are using socio-economic and technological data for calculating characterization factors and that they constantly need to be updated to reflect the current situation. Among the depletion-oriented model, AADP is theoretically the most indicated for a study on recycling and circular economy, as it expands the modelling to urban mining. When strategic assessment of specific resources is needed, models such as those applied for critical raw materials may help expanding the focus of the assessment, as they include more resources and magnify their importance. Beyond the specific perspective in assessing those resources, the sensitivity is extremely helpful for highlighting which resources are somehow of higher relevance, given their relative contribution from different points of view (e.g. Ag, which is a high contributor in all the models that compare current consumption with availability, including those that 
have as numerator the supply risk; $\mathrm{Cu}$ is almost always present, popping up when assuming extra cost for future extraction, etc.). Given the different substance coverage and underpinning assumptions, the sensitivity could be seen as a way to complement the models, ranking substances by their relevance under different perspectives. Besides, many resources that could be recovered by recycling have no characterization factors at the moment in any impact characterization model. This may lead to a potential underestimation of the benefit of the recycling.

Building on the present case study, our recommendations for improving interpretation of case studies related to circular economy could be summarized as follows:

- Regarding toxicity-related impact categories, it is recommended to (1) run different models for toxicity, focusing on commonalities in prioritization of the substances contributing the most to the overall impact and (2) perform the assessment with and without long-term emissions to appreciate the contribution of the long-term emissions.

- Regarding resource-related impacts, it is recommended to (1) run models that include considerations related to recycling potentials and anthropogenic stock availability, such as the AADP, and (2) complete the assessment running a sensitivity with other models which may highlight the relative importance of specific resources under different socio-economic perspectives.

In the context of circular economy strategies, LCA may help to ensure that the recovery of resources is not posing additional burdens on the environment and that avoided impacts are systematically accounted for beyond a mere energyrelated perspective. However, the assessment should be always coupled with a sensitivity analysis to support sound interpretation and to guide future improvements.

\section{Compliance with ethical standards}

Conflict of interest The authors declare that they have no conflict of interest.

Open Access This article is distributed under the terms of the Creative Commons Attribution 4.0 International License (http:// creativecommons.org/licenses/by/4.0/), which permits unrestricted use, distribution, and reproduction in any medium, provided you give appropriate credit to the original author(s) and the source, provide a link to the Creative Commons license, and indicate if changes were made.

\section{References}

Bakas I, Hauschild MZ, Astrup TF, Rosenbaum RK (2015) Preparing the ground for an operational handling of long-term emissions in LCA. Int J Life Cycle Assess 20:1444-1455
Biganzoli L, Falbo A, Forte F, Rigamonti L, Grosso M (2015) Mass balance and life cycle assessment of waste electrical and electronic equipment management system implemented in Lombardia region (Italy). Sci Total Environ 524-525:361-375

Brogaard LK, Damgaard A, Jensen MB, Barlaz M, Christensen TH (2014) Evaluation of life cycle inventory data for recycling systems. Resour Conserv Recy 87:30-45

Cellura M, Longo S, Mistretta M (2011) Sensitivity analysis to quantify uncertainty in life cycle assessment: the case study of an Italian tile. Renew Sust Energ Rev 15(9):4697-4705

Clavreul J, Guyonnet D, Christensen TH (2012) Quantifying uncertainty in LCA-modelling of waste management systems. Waste Manag 32(12):2482-2495

CML (2012) CML-IA model and characterisation factors. Available from http://cml.leiden.edu/software/data-cmlia.html\#downloads. Accessed November 2015

Dewulf J, Benini L, Mancini L, Sala S, Blengini GA, Ardente F, Recchioni M, Maes J, Pant R, Pennington D (2015) Rethinking the area of protection 'natural resources' in life cycle assessment. Environ Sci Technol 49(9):5310-5317

Dong Y, Gandhi N, Hauschild MZ (2014) Development of comparative toxicity potentials of 14 cationic metals in freshwater. Chemosphere 112:26-33

Ekvall T, Assefa G, Bjorklund A, Erikson O, Finnveden G (2007) What life-cycle assessment does and does not do in assessments of waste management. Waste Manag 27:989-996

European Commission (EC) (2013) Commission Recommendation of 9 April 2013 on the use of common methods to measure and communicate the life cycle environmental performance of products and organisations (2013/179/EU). Official Journal of the European Union, Volume 56, 4 May 2013

EC (2014) Report on critical raw materials for the EU - Report of the Ad hoc Working Group on defining critical raw materials. Available at https://ec.europa.eu/growth/tools-databases/eip-rawmaterials/en/community/document/critical-raw-materials-eu-reportad-hoc-working-group-defining-critical-raw. Accessed November 2015

European Commission - Joint Research Centre (EC-JRC) (2010) ILCD handbook - general guide for life cycle assessment - detailed guidance. European Commission, Joint Research Centre. Institute for Environment and Sustainability

Finnveden G, Hauschild MZ, Ekvall T, Guinée J, Heijungs R, Hellweg S (2009) Recent developments in life cycle assessment. J Environ Manag 91:1-21

Gandhi N, Diamond ML, Huijbregts MA, Guinée JB, Peijnenburg WJ, van de Meent D (2011) Implications of considering metal bioavailability in estimates of freshwater ecotoxicity: examination of two case studies. Int J Life Cycle Assess 16(8):774-787

Gaudreault C, Samson R, Stuart P (2009) Implications of choices and interpretation in LCA for multi-criteria process design: de-inked pulp capacity and cogeneration at a paper mill case study. J Clean Prod 17(17):1535-1546

Goedkoop M, Heijungs R, Huijbregts M, de Schryver A, Struijs J, van Zelm R (2009) ReCiPe 2008. A life cycle assessment method which comprises harmonized category indicators at the midpoint and the endpoint level. Report I: Characterisation. Ministry of Housing, Spatial Planning and Environment, Amsterdam

Hauschild M, Wenzel H (1998) Environmental assessment of products. Vol. 2 - Scientific background. Chapman \& Hall, UK, Kluwer Academic Publishers, Hingham, USA

Hauschild M, Olsen SI, Hansen E, Schmidt A (2008) Gone... but not away-addressing the problem of long-term impacts from landfills in LCA. Int J Life Cycle Ass 13(7):547-554

Heijungs R, Kleijn R (2001) Numerical approaches towards life cycle interpretation five examples. Int J Life Cycle Assess 6(3):141-148 
Huang Y, Spray A, Parry T (2013) Sensitivity analysis of methodological choices in road pavement LCA. Int J Life Cycle Assess 18(1):93-101

Huijbregts MA, Gilijamse W, Ragas AM, Reijnders L (2003) Evaluating uncertainty in environmental life-cycle assessment. A case study comparing two insulation options for a Dutch one-family dwelling. Envir Sci Tech 37(11):2600-2608

ISO 14040 (2006) Environmental management—-life cycle assessmentprinciples and framework. Geneva, Switzerland

ISO 14044 (2006) Environmental management—life cycle assessmentrequirements and guidelines. Geneva, Switzerland

Klinglmair M, Sala S, Brandão M (2014) Assessing resource depletion in LCA: a review of methods and methodological issues. Int $\mathrm{J}$ Life Cycle Assess 19(3):580-592

Lim SR, Schoenung JM (2010) Human health and ecological toxicity potentials due to heavy metal content in waste electronic devices with flat panel displays. J Hazard Mater 177(1):251-259

Mancini L, De Camillis C, Pennington D (eds) (2013) Security of supply and scarcity of raw materials. Towards a methodological framework for sustainability assessment. European Commission, Joint Research Centre, Institute for Environment and Sustainability, Publications Office of the European Union, Luxemburg Report EUR 26086 EN, pp 71

Mancini L, Benini L, Sala S (2015a) Resource footprint of Europe: complementarity of material flow analysis and life cycle assessment for policy support. Environ Sci Pol 54:367-376

Mancini L, Benini L, Goralczyk M, Recchioni R, Sala S, Pennington DW (2015b) The potential of life cycle assessment for managing critical raw materials and supporting resource policy. Int J Life Cycle Assess 20(1):100-116

Mancini L, Benini L, Sala S (2016) Characterization of raw materials based on supply risk indicators for Europe. Int J Life Cycle Assess. doi:10.1007/s11367-016-1137-2

Pettersen J, Hertwich EG (2008) Critical review: life-cycle inventory procedures for long-term release of metals. Envir Sci Tech 42(13): 4639-4647

Pizzol M, Christensen P, Schmidt J, Thomsen M (2011) Impacts of "metals" on human health: a comparison between nine different methodologies for life cycle impact assessment (LCIA). J Clean Prod 19(6):646-656

Prado-Lopez V, Seager TP, Chester M, Laurin L, Bernardo M, Tylock S (2014) Stochastic multi-attribute analysis (SMAA) as an interpretation method for comparative life-cycle assessment (LCA). Int J Life Cycle Assess 19(2):405-416

Rigamonti L, Falbo A, Grosso M (2013a) Improvement actions in waste management systems at the provincial scale based on a life cycle assessment evaluation. Waste Manag 33:2568-2578
Rigamonti L, Falbo A, Grosso M (2013b) Improving integrated waste management at the regional level: the case of Lombardia. Waste Manage Res 31(9):946-953

Rigamonti L, Grosso M, Giugliano M (2010) Life cycle assessment of sub-units composing a MSW management system. J Clean Prod 18: $1652-1662$

Rosenbaum RK, Bachmann TM, Swirsky Gold L, Huijbregts MAJ, Jolliet O, Juraske R, Koehler A, Larsen HF, MacLeod M, Margni M, McKone TE, Payet J, Schuhmacher M, van de Meent D, Hauschild MZ (2008) USEtox - the UNEP-SETAC toxicity model: recommended characterisation factors for human toxicity and freshwater ecotoxicity in life cycle impact assessment. Int J Life Cycle Assess 13:532-546

Sala S, Wolf MA, Pant R (2012) Characterization factors of the ILCD recommended life cycle impact assessment methods. Database and supporting information. First edition EUR25167EN. ISBN 978-9279-22727. Luxembourg: Publications Office of the European Union. Available at http://eplca.jrc.ec.europa.eu/uploads/2014/01/LCIAcharacterization-factors-of-the-ILCD.pdf

Schneider L, Berger M, Finkbeiner M (2011) The anthropogenic stock extended abiotic depletion potential (AADP) as new parameterization to model the depletion of resources. Int J Life Cycle Assess 16(9):929-936

Schneider L, Berger M, Finkbeiner M (2015) Abiotic resource depletion in LCA - background and update of the anthropogenic stock extended abiotic depletion potential (AADP) model. Int J Life Cycle Assess 20(5):709-721

Steen BA (1999) A systematic approach to environmental priority strategies in product life development (EPS). Version 2000-Models and data of the default method. Chalmers University, Lindholmen/ Johanneberg

Steen BA (2006) Abiotic resource depletion different perceptions of the problem with mineral deposits. Int J Life Cycle Assess 11(1):49-54

Swiss Centre for Life Cycle Inventories (2010) Ecoinvent: the life cycle inventory data, version 2.2

UNEP (2011) Recycling rates of metals - a status report, a report of the Working Group on the Global Metal Flows to the International Resource Panel. Graedel TE, Allwood J, Birat J-P, Reck BK, Sibley SF, Sonnemann G, Buchert M, Hagelüken C

UNEP (2013) Metal recycling: opportunities, limits, infrastructure, a Report of the Working Group on the Global Metal Flows to the International Resource Panel. Reuter MA, Hudson C, van Schaik A, Heiskanen K, Meskers C, Hagelüken C

Van Hoof G, Vieira M, Gausman M, Weisbrod A (2013) Indicator selection in life cycle assessment to enable decision making: issues and solutions. Int J Life Cycle Assess 18:1568-1580 